\title{
PRÁTICAS DE GOVERNAMENTO EM LIVROS DE FORMAÇÃO DE PROFESSORES DE EDUCAÇÃO INFANTIL: SENSIBILIDADES, DISPOSIÇÕES E CONSCIENTIZAÇÕES EM DISCURSO
}

\author{
GOVERNING PRACTICES IN EDUCATIONAL BOOKS FOR EARLY CHILDHOOD \\ EDUCATION TEACHERS: SENSITIVITY, \\ DISPOSITIONS AND AWARENESS IN DISCOURSE
}

\section{PRÁCTICAS DE GOBERNAMIENTO EN LIBROS DE FORMACIÓN DE PROFESORES DE EDUCACIÓN INFANTIL: SENSIBILIDADES, DISPOSICIONES Y CONCIENCIACIONES EN DISCURSO}

Rodrigo Saballa de Carvalho ${ }^{1}$

\begin{abstract}
RESUMO
O artigo é decorrente de uma pesquisa cujo objetivo foi problematizar as práticas de governamento docente veiculadas pelo discurso da pedagogia histórico-crítica presente em livros de formação de professores de Educação Infantil. A materialidade investigativa da pesquisa foi composta por um conjunto de livros que defendem o ensino de conteúdos emergentes de áreas do conhecimento para bebês e crianças pequenas, além de apresentarem uma crítica ao que nomeiam processo de desescolarização e fetichização da infância. Metodologicamente, a partir das contribuições dos estudos desenvolvidos por Michel Foucault, dentre outros autores vinculados a uma perspectiva pós-estruturalista, foi analisado como os livros que constituem o corpus investigativo, por meio da defesa de uma pedagogia histórico-crítica, regulam, organizam e divulgam modos considerados adequados de exercício da docência na Educação Infantil. Dessa forma, com base nas análises, foi descrita a arquitetura formativa dos livros, bem como problematizadas as táticas discursivas presentes nos textos, cujo intuito é a produção de formas de ser docente, através da universalização de um modelo de raciocínio pautado na escolarização precoce das crianças. Nesse sentido, o exercício analítico das práticas de governamento identificadas nos livros possibilitou discutir a naturalização dos enunciados constituintes do discurso da pedagogia histórico-crítica, evidenciando seus efeitos de verdade. Isso porque assumir a dimensão constitutiva da linguagem e enfrentar o desafio de questionar os efeitos de verdade dos discursos que operam no governamento da formação docente consistem em uma atitude ética na atualidade.
\end{abstract}

PALAVRAS-CHAVE: Educação Infantil. Livro. Formação Docente. Discurso. Docência.

\section{ABSTRACT}

The article is the result of a research whose objective was to problematize the practices of governing teachers conveyed by the historical-critical pedagogy discourse present in teacher education books of Early Childhood Education. The research's evidence was composed of a set of books that defend the teaching of emerging contents of knowledge areas for infants and young children, as well as present a critique of what they call the

\footnotetext{
${ }^{1}$ Pós-Doutor em Educação - Universidade Federal de Pelotas (UFPel) - Pelotas, RS - Brasil. Doutor em Educação - Universidade Federal do Rio Grande do Sul (UFRGS) - Professor do Programa de Pós-Graduação em Educação. Professor da área de Educação Infantil Universidade Federal do Rio Grande do Sul (UFRGS) Farroupilha, Porto Alegre, RS - Brasil. E-mail: rsaballa@terra.com.br

Submetido em: 12/11/2017 - Aceito em: 12/06/2018
}

(C) ETD-Educação Temática Digital Campinas, SP $\quad$ v.21 n.1 $\quad$ p.84-104 jan./mar. 2019 
process of deschooling and fetishization of childhood. Methodologically, based on the contributions of the studies developed by Michel Foucault, among other authors linked to a post-structuralist perspective, we analyzed how the books that constitute the investigative corpus, through the defense of a historical-critical pedagogy, regulate, organize and spread modes considered suitable for teaching in Early Childhood Education. Thus, based on the analyses, the formative architecture of the books was described, and the discursive tactics present in the texts were problematized, whose purpose is the production of modes of being teachers, through the universalization of a model of reasoning based on the early schooling of children. In this sense, the analytical exercise of the governing practices identified in the books made it possible to discuss the naturalization of the assertions that constitute the historical-critical pedagogy discourse, evidencing its effects of truth. Accepting the constitutive dimension of language and facing the challenge of questioning the effects of truth of the discourses that operate in governing teacher education is an ethical stand nowadays.

KEYWORDS: Early Childhood Education. Book. Teacher Education. Discourse. Teaching.

\section{RESUMEN}

El artículo resulta de una investigación cuyo objetivo fue problematizar prácticas de gobernamiento docente difundidas por el discurso de la pedagogía histórica crítica presente en libros de formación de profesores de Educación Infantil. La materialidad investigativa fue compuesta por libros que defienden la enseñanza de contenidos de las áreas del conocimiento para bebés y niños pequeños, además de presentar una crítica al proceso de desescolarización y fetichización de la infancia. Metodológicamente, tras las contribuciones de los estudios de Michel Foucault, y otros autores vinculados a una perspectiva postestructuralista, se analizó cómo los libros que constituyen el corpus investigativo, por medio de la defensa de una pedagogía histórica crítica, regulan, organizan y divulgan modos considerados adecuados de ejercicio de la docencia en la Educación Infantil. Así, con base en los análisis, se describió la arquitectura formativa de los libros y problematizaron las tácticas discursivas presentes en los textos, cuya intención es producir formas de docencia, a través de la universalización de un modelo de raciocinio pautado en la escolarización precoz de los niños. En este sentido, el ejercicio analítico de las prácticas de gobernamiento identificadas en los libros posibilitó discutir la naturalización de enunciados constituyentes del discurso de la pedagogía histórica crítica, evidenciando sus efectos de verdad. Esto porque asumir la dimensión constitutiva del lenguaje y enfrentar el reto de cuestionar los efectos de verdad de los discursos que operan en el gobernamiento de la formación docente consiste en una actitud ética en la actualidad.

PALABRAS CLAVE: Educación Infantil. Libro. Formación docente. Discurso. Docencia.

\section{CONSIDERAÇÕES INICIAIS}

[...] o que se pretende formar e transformar não é apenas o que o professor faz ou o que sabe, mas, fundamentalmente, sua própria maneira de ser em relação ao seu trabalho. (LARROSA, 1994, p. 50)

Contemporaneamente, é possível observar, de forma cada vez mais recorrente, que o governamento ${ }^{2}$ docente, entendido como modo de condução da conduta de si e dos outros (DEAN, 1999; FOUCAULT, 2008; DARDOT; LAVAL, 2016), tem encontrado "nas práticas pedagógicas (ensino, instrução, educação, formação, aprendizagem) sua principal e quiçá mais eficiente forma de desdobramento" (MARÍN-DÍAZ; NOGUERA-RAMIREZ, 2011, 132). Isso significa que o governamento, por meio de diferentes práticas pedagógicas, nas

\footnotetext{
${ }^{2}$ Inspirado na discussão desenvolvida por Veiga-Neto (2002), convém destacar que será utilizado o termo governamento ao invés de governo nos casos em que estiver sendo abordada a ação ou o ato de governar.
}

(C) ETD-Educação Temática Digital Campinas, SP $\quad$ v.21 n.1 $\quad$ p.84-104 jan./mar. 2019 
quais se inclui a formação docente, tem intensificado a produção do autogoverno dos professores, deixando "de remeter à disciplina para alcançar o mais íntimo" (DARDOT; LAVAL, 2016, p. 18) desses sujeitos. Ratificando o argumento, Marín-Díaz (2012, p. 19) afirma que "cada vez é mais claro que a preocupação pelo governamento de si e dos outros se encontra no âmago da constituição de um campo de saberes, noções, conceitos e práticas relativas à educação e à pedagogia", os quais se materializam por meio de artefatos da cultura (livros, filmes, propagandas, jornais, revistas, novelas, séries televisivas, etc.) endereçados aos professores.

Diante do exposto, convém situar que este artigo é decorrente de uma pesquisa cujo objetivo foi problematizar as práticas de governamento (DEAN, 1999; FOUCAULT, 2008) docente veiculadas pelo discurso da pedagogia histórico-crítica (SAVIANI, 2000; ARCE, 2013; PASQUALINI, 2010; PINA, 2014; LAZARETTI; MELO, 2018) presente em livros de formação de professores de Educação Infantil. Portanto, a partir das contribuições dos estudos desenvolvidos por Michel Foucault (1995, 2005, 2007, 2008), dentre outros autores vinculados a uma perspectiva pós-estruturalista (PALAMIDESSI, 1996; POPKEWITZ, 1998, 2001; GARCIA, 2002; BUJES, 2009; MARÍN-DÍAZ; NOGUERA-RAMIREZ, 2011; MARÍN-DÍAZ, 2012; BOCCHETTI; BUENO, 2012), serão analisados como livros de formação de professores de Educação Infantil promovem modos particulares de agir, sentir, falar, ver o mundo e o eu docente (POPKEWITZ, 1998).

Para melhor compreender tal investida, cabe destacar que a materialidade investigativa da pesquisa foi composta por um conjunto de livros ${ }^{3}$ (ARCE; MARTINS, 2009; ARCE; MARTINS, 2010; ARCE; SILVA; VAROTTO, 2011; ARCE; JACOMELLI, 2012; ARCE, 2013; ARCE, 2014), referenciados na pedagogia histórico-crítica, os quais defendem o ensino de conteúdos emergentes de áreas do conhecimento como "geradores de desenvolvimento nas crianças" (ARCE, 2016), em oposição aos estudos que têm reivindicado, nas últimas décadas, a pedagogia da infância (ROCHA, 2001; BARBOSA, 2010) como princípio da prática docente em creches e pré-escolas. Nesse sentido, primeiramente, deve-se esclarecer que a pedagogia da infância, enquanto campo de pesquisa e de ação pedagógica na Educação Infantil, "compreende que toda e qualquer ação educativa exige considerar as crianças e os contextos socioculturais que definem sua infância" (BARBOSA, 2010, p. 21). Isso porque tal pedagogia apoia: 1) a formação integral das crianças, para além de uma lógica propedêutica de preparação para o ensino fundamental através do ensino de conteúdos escolares (ROCHA, 2001); 2) o foco da ação pedagógica docente na promoção e diversificação de

\footnotetext{
3 Os livros que constituem o corpus de análise da pesquisa foram produzidos no período de seis anos consecutivos (2009-2014). Cabe esclarecer que somente a obra de Arce e Jacomelli (2012) foi publicada pela editora Autores Associados; todas as demais foram produzidas pela Editora Alínea.
}

(C) ETD-Educação Temática Digital Campinas, SP $\quad$ v.21 n.1 $\quad$ p.84-104 jan./mar. 2019 
experiências que resultem em aprendizagens e conhecimentos significativos para as crianças (ROCHA, 2001); 3) a construção de um currículo que tenha como eixos norteadores as interações e as brincadeiras, tendo em vista o comprometimento com as bases da formação humana das crianças (ROCHA; BARBOSA, 2010) em seus aspectos éticos, políticos e estéticos; 4) uma ação pedagógica docente comprometida política e socialmente, que dê suporte às aprendizagens das crianças, por meio de um contexto educativo que leve em consideração tempos, espaços, materiais e as relações entre os sujeitos.

Por outro lado, é importante reiterar que a pedagogia referenciada nos livros analisados é definida a partir de outros pressupostos. Ou seja, no âmbito da pedagogia histórico-crítica na Educação Infantil, defende-se: 1) a compreensão de que o objetivo da escola é a "transmissão-assimilação do saber sistematizado" (SAVIANI, 2000, p. 23), com base em uma perspectiva marxista de formação humana (PINA, 2014); 2) uma concepção de desenvolvimento humano referenciada nas contribuições da psicologia histórico-cultural, a qual "refuta a compreensão do desenvolvimento como processo espontâneo e natural" (PASQUALINI, 2010, p. 188) e valoriza "a importância das condições de vida, educação e intervenção do adulto" (PASQUALINI, 2010, p. 189) na docência com as crianças; 3) o investimento na ideia de que o aspecto fundamental "do currículo reside na identificação de quais elementos culturais precisam ser assimilados pelos indivíduos de modo a se promover sua humanização" (PASQUALINI, 2018, p. 10); 4) o ato de ensinar como eixo nuclear do trabalho pedagógico do professor (PINA, 2014); 5) o entendimento de que "um trabalho sequencial, organizado e dirigido desde a Educação Infantil pode significar aos alunos um importante passo no processo de apropriação dos conhecimentos" (PINA, 2014, p. 148-149) historicamente produzidos pela humanidade; 6) a aposta de que "a finalidade da educação escolar é formar a segunda natureza no sujeito - funções psicológicas superiores", através do ensino sistematizado (LAZARETTI; MELLO, 2018, p. 119) de conteúdos escolares, advindos do "conhecimento científico, filosófico e artístico produzido pela humanidade" (PINA, 2014, p. 129); 7) a concepção de que "o ensino é a produção intencional da necessidade de conhecer, explorar, descobrir e, que para isso a transmissão, reprodução e imitação são essenciais" (ARCE, 2013, p. 10); 8) a indicação de que o professor, através do ensino, deve levar "a criança a incorporar uma forma de pensar e analisar o mundo" (ARCE, 2016, p. 106) que seja emergente do conhecimento científico; 9) a noção de que o professor "deve desenvolver culturalmente a criança, formar o novo em seu desenvolvimento e produzir saltos qualitativos nas funções psicológicas superiores" (LAZARETTI; MELLO, 2018, p. 131). Em suma, conforme esclarece Arce (2013, p. 6), a pedagogia histórico-crítica preconiza "as possibilidades do 'ensinar', do 'dirigir' intencionalmente o desenvolvimento" (ARCE, 2013, p. 6) das crianças, refutando o ideário antiescolar na Educação Infantil (PASQUALINI, 2010) que tem sido difundido pelos pesquisadores defensores da pedagogia da infância (ARCE, 2013).

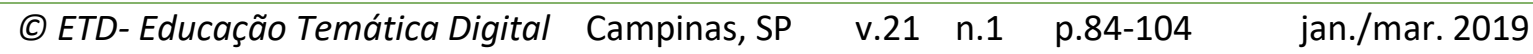


Desse modo, a partir da leitura dos livros que constituem o corpus investigativo, foi definida a pedagogia histórico-crítica (SAVIANI, 2000; ARCE, 2013; PASQUALINI, 2010; PINA, 2014; LAZARETTI; MELO, 2018) na Educação Infantil como eixo analítico, pelo fato de ser (como toda e qualquer pedagogia) uma produtora de discursos difusores de saberes, exercícios, práticas e "táticas de governamento ético" (MARÍN-DÍAZ, 2012), cujo objetivo é regular, organizar e divulgar modos considerados adequados de exercício da docência com as crianças. Partindo desses apontamentos, é importante salientar que foi possível identificar, nas obras analisadas, a presença de modos peculiares de produzir sentidos e conduzir as condutas (DEAN, 1999) docentes, com base em táticas discursivas (SOBRAL, 2013) específicas evidentes nos textos, como "contrastes, repetições e exemplos" (SOBRAL, 2013). A finalidade dessas táticas é produzir formas de ser docente, por meio da universalização de um "modelo de raciocínio" (POPKEWITZ, 1998) pautado na escolarização precoce das crianças.

Sendo assim, pode-se afirmar, em suma, que a discussão a ser apresentada abordará os modos como os enunciados que constituem o discurso da pedagogia histórico-crítica, investidos de prescrições e regulações morais (BUJES, 2009), adquirem valor de verdade ao funcionarem como práticas de governamento que ensinam o professor a conduzir sua profissão em nome de determinado estilo de docência. Ademais, o texto pretende contribuir para a problematização da lógica propedêutica de educação das crianças, evidenciando que não existe um modelo exclusivo de exercício da docência na Educação Infantil, mas múltiplos modos de atuação, sempre constituídos dentro de determinadas ordens do discurso (FOUCAULT, 2005).

O artigo está organizado em cinco seções. Após esta seção introdutória, a segunda seção apresentará os conceitos de discurso (FOUCAULT, 2005, 2008) e governamento (FOUCAULT, 2008; DARDOT; LAVAL, 2016) como ferramentas conceituais. Na terceira seção, será descrita e discutida a arquitetura formativa (BOCCHETTI; BUENO, 2012) das obras. Na quarta seção, serão problematizadas as táticas discursivas (SOBRAL, 2013) presentes nos livros que operam no governamento docente. Por fim, na última seção, serão apresentadas as considerações finais do artigo.

\section{ABRINDO A CAIXA DE FERRAMENTAS: OS CONCEITOS DE DISCURSO E GOVERNAMENTO COMO PAUTA}

Assumindo a perspectiva de que "o sujeito é uma função do discurso" (GARCIA, 2002, p. 24) e de que é por meio da linguagem que as "experiências culturais, sociais, emocionais e políticas podem ser nomeadas, fixadas, aprisionadas e definidas pelas posições e diferenças que os discursos da pedagogia mesmo que provisoriamente assinalam" (GARCIA, 2002, p. 24), o conceito de discurso (FOUCAULT, 2005, 2007, 2008) se

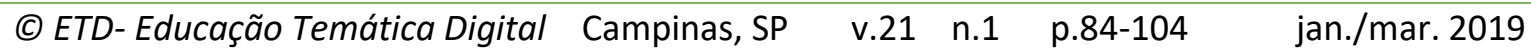


constitui uma ferramenta de extrema relevância no contexto das análises a serem apresentadas.

Com efeito, discurso é compreendido "como um conjunto de enunciados que se apoia em uma mesma formação discursiva" (FOUCAULT, 2007, p. 132). Associado a tal definição, o discurso, enquanto produtor de verdades (FOUCAULT, 2005, 2008), é "um bem finito, limitado, desejado, útil - que tem suas regras de desaparecimento e suas condições de apropriação e utilização" (FOUCAULT, 2007, p. 136). Nesse sentido, o discurso pode ser considerado "uma prática modelizadora da realidade, hierarquizadora e articuladora de relações específicas entre o visível e o dizível" (PALAMIDESSI, 1996, p. 193). Dito de outro modo, é o discurso que "permite nomear e dar sentido ao mundo ou ao que comumente se denomina por realidade" (GARCIA, 2002, p. 22).

No entanto, é importante que se deixe claro que o discurso somente tem sentido a partir de sua exterioridade, e não a partir da lógica interna de seus enunciados (FOUCAULT, 2007). Isso porque o indivíduo não constrói sentidos e significados de maneira livre, mas por meio de uma série de sistemas de restrições e incitações discursivas constituidoras de determinada ordem (FOUCAULT, 2005; BOCCHETTI; BUENO, 2012). Portanto, pode-se afirmar que o discurso é "uma força constituinte do sujeito, das posições e ordenamentos que tornam possível categorizar um sujeito, atribuindo-lhe um estatuto social, restringindo e incentivando suas ações" (PALAMIDESSI, 1996, p. 192).

Ademais, é necessário destacar que o discurso "institui campos de objetos, concorre na produção de formas de subjetividade, estabelece diferenciações, presenças, exclusões, saberes e verdades acerca de como pensar, ser e agir" (GARCIA, 2002, p. 26). Como se pode perceber, essa perspectiva conceitual possibilita analisar as diferentes maneiras pelas quais os discursos cumprem certas funções dentro de sistemas estratégicos, nos quais o poder se encontra implicado e pelo qual opera (FOUCAULT, 1995). Isso reforça o entendimento de que os discursos precisam ser lidos como monumentos, a partir dos quais se tem a possibilidade de operar analiticamente sobre a sua superfície (FOUCAULT, 2007). Essa compreensão viabiliza depreender que não existe nada por trás dos discursos (FOUCAULT, $2005,2007)$. O que existe é a possibilidade de problematizar o funcionamento e a produtividade dos discursos "nos modos como constituem, medeiam, regulam e modificam a experiência" (MARÍN-DÍAZ, 2012, p. 27) que os indivíduos têm de si mesmos.

Essa perspectiva conceitual é importante precisamente porque propicia a análise das obras que constituem o corpus investigativo, já que não existe nenhuma pedagogia prédiscursiva ou fora do discurso (GARCIA, 2002). Assim, é "a ordem do discurso pedagógico que permite aos seus enunciados se inscreverem em certo horizonte teórico" (BUJES, 2009, p. 285), estabelecendo regras e padrões que orientam os indivíduos ao produzir

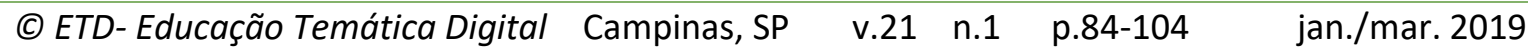


conhecimento sobre o mundo (POPKEWITZ, 1998) e a "constituir os princípios das realidades" (POPKEWITZ, 2001, p. 140).

A esse respeito, dois esclarecimentos são necessários. Em primeiro lugar, não existe, nas obras analisadas, uma essência a ser evidenciada sobre a docência na Educação Infantil, mas práticas de governamento (FOUCAULT, 2008) que operam com base nos enunciados constituintes do discurso da pedagogia histórico-crítica, indicando uma docência a ser vivenciada pelos leitores. Isso significa que, nas obras, é descrito um "aparato conceitual que organiza as tecnologias de ensino e, em certo sentido, um conhecimento instrumental, sobre a maneira como os professores" (POPKEWITZ, 2001, p. 88) devem atuar.

Em segundo lugar, as proposições constantes nas obras a respeito de como deve ser a educação das crianças encontram-se em uma ordem do discurso (FOUCAULT, 2005, 2007) que busca organizar a realidade, instituindo parâmetros por meio dos quais os professores são incitados a se verem, a se entenderem e a agirem no cotidiano de sua prática pedagógica (LARROSA, 1994). Dessa maneira, o conhecimento didático veiculado nos livros, ao orientar a prática docente, "imprime uma certa seletividade naquilo que os professores veem, pensam, sentem e conversam sobre as crianças e os assuntos escolares" (POPKEWITZ, 2001, p. 13).

Nessa direção, é preciso destacar que os livros do corpus de análise estabelecem regimes de verdade (FOUCAULT, 1995) ${ }^{4}$, através de enunciados que incitam o leitor a se autoavaliar (LARROSA, 1994), tendo em vista tornar sua prática docente a mais próxima possível da pedagogia histórico-crítica referenciada nas publicações. Com base nesses pressupostos, Palamidessi (1996, p. 197) afirma que os regimes de verdade "situam os professores como consumidores de definições discursivas, desautorizando suas palavras na medida em que as mesmas não coincidam com as definições" e orientações propostas. Assim, parece que as obras em análise, enquanto "mobilizadoras de práticas educativas, promovem e divulgam, ampla e massivamente todo um conjunto de exercícios e técnicas de condução dos leitores por eles mesmos" (MARÍN-DÍAZ, 2012, p. 18).

Diante disso, podem-se problematizar os enunciados que constituem o discurso da pedagogia histórico-crítica veiculados nos livros, já que estes jamais "governam contra a liberdade ou a despeito da liberdade, mas governam pela liberdade, isto é, agem ativamente no espaço de liberdade dado aos indivíduos para que estes venham a conformar-se por si mesmos a certas normas" (DARDOT; LAVAL, 2016, p. 18-19). Partindo desse panorama, o que está em jogo nas obras é a produção de uma subjetividade docente (GARCIA, 2002) pautada pela defesa de que o ensino de conteúdos por áreas de

\footnotetext{
${ }^{4} \mathrm{O}$ regime de verdade é definido conceitualmente como "um conjunto de procedimentos regulados para a produção, a lei, a repartição, a circulação e o funcionamento dos enunciados" (FOUCAULT, 1995, p. 14).
}

(C) ETD- Educação Temática Digital Campinas, SP $\quad$ v.21 n.1 $\quad$ p.84-104 jan./mar. 2019 
conhecimento e a correlata preparação das crianças para as etapas subsequentes de ensino são os aspectos basilares da ação pedagógica do professor. Tal argumento poderá ser observado nos excertos do material de análise apresentados na sequência:

\begin{abstract}
...] a criança precisa ser ensinada e o seu ato de assimilação envolverá a reprodução, a repetição, o esforço com o fim de alcançar-se a automação. (ARCE, 2010, p. 32)

Os defensores da chamada pedagogia da infância ou pedagogia da educação infantil ou pedagogia de Reggio advogam a 'não escolarização', em razão de conceituarem tal termo como um processo de ensino meramente transmissivo, ligado à forma como os escolanovistas entendiam tal termo. (PRADO; AZEVEDO, 2012, p. 47)
\end{abstract}

Esta ideia, que liga a Educação Infantil ao brincar, à liberdade, é recorrente seja no meio acadêmico, seja no cotidiano das escolas. Entretanto, por mais atrativa que possa parecer esta ideia, ela ignora o conhecimento já acumulado a respeito do desenvolvimento infantil e, também o conjunto de pesquisas existentes a respeito de como as crianças se desenvolvem e, quais são as possibilidades para as educarmos. (ARCE, 2013, p. 18)

Contrariamente ao que vem sendo defendido na área, pensar que tipo de conhecimento deve ser priorizado nessa etapa não significa 'tirar das crianças' o seu direito à infância quando o professor intervém ou direciona as atividades pedagógicas no contexto da educação infantil. (PRADO; AZEVEDO, 2012, p. 34)

Portanto, a escola começa na educação infantil, e o ensino também. (PRADO; AZEVEDO, 2012, p. 50)

Através da leitura, é notório que a docência descrita nos livros é a de um professor que deve ensinar os bebês e as crianças pequenas por meio da transmissão de conteúdos escolares pautados em áreas do conhecimento. As obras parecem indicar que o caminho para a qualificação das práticas docentes é o resgate "da escola eficaz e do professor eficiente e autêntico" (POPKEWITZ, 2001, p. 15). Para tanto, as autoras utilizam tecnologias nas quais a pedagogia histórico-crítica se encontra "centralmente implicada em compô-las, organizando, articulando e permitindo que sejam colocados em ação certos modos de pensar e de falar" (BUJES, 2009, p. 271) sobre como deve ser a ação docente. Tal prerrogativa corrobora a visão de que o mundo "é baseado na certeza e em práticas organizadas com lógica" (POPKEWITZ, 2001, p. 15).

Nessa perspectiva, as práticas pedagógicas descritas podem ser consideradas "ações reguladas destinadas à formação e à definição de modos de comportamento dos outros" (MARÍN-DIAZ, 2012, p. 37). Isso implica afirmar que a formação docente decorrente da pedagogia histórico-crítica enunciada nos livros pode ser considerada uma problemática de governamento (FOUCAULT, 2008) se tal conceito for entendido como "um domínio prático e técnico, cuja finalidade é a de potencializar a capacidade de alguns para agirem sobre as condutas alheias" (BUJES, 2009, p. 270). Assim, parece que a capacidade de agir sobre as

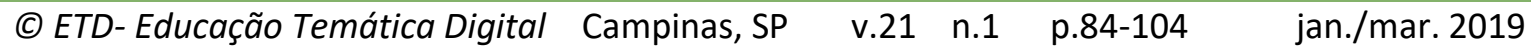


condutas dos leitores ocorre a partir de normas particulares que se operacionalizam através de táticas discursivas (GARCIA, 2002) presentes nos textos, as quais procuram, com o emprego de uma variedade de técnicas e saberes, exercer o governamento (DEAN,1999) por meio das escolhas, desejos, aspirações e identificações dos leitores.

É, então, possível esclarecer que o conceito de governamento é compreendido como "qualquer sentido mais ou menos calculado de direção de comportamentos e ações" (DEAN, 1999 , p. 2). Em outras palavras, o governamento caracteriza-se pela unificação de estratégias que objetivam atingir fins políticos, conduzindo a todos e a cada um, através de um processo que, ao mesmo tempo, individualiza, totaliza e normaliza (FOUCAULT, 2008).

Nessa lógica, é importante evidenciar que a questão em pauta nas práticas de governamento é a produção de indivíduos intervenientes nos jogos e nas relações de poder, os quais supostamente possuem mais autonomia e liberdade para realizar as suas escolhas no âmbito de determinadas formas de ação. Isso porque, de acordo com Dean (1999), os desejos, os sentimentos, as aspirações, os planos, assim como as capacidades subjetivas dos indivíduos, tornam-se potentes objetos a serem governados. Isto é, trata-se da conversão de um conjunto de finalidades particulares (e aparentemente pessoais) em modos de potencialização da prática dos docentes, enquanto prerrogativa para estruturar seu campo de atuação (BUJES, 2009).

Cabe, também, à guisa de conclusão desta seção, salientar que os discursos sobre a prática pedagógica veiculados pelos livros operam o governamento (DEAN, 1999; FOUCAULT, 2008; DARDOT; LAVAL, 2016) docente por meio de "repetições, contrastes e exemplos" (SOBRAL, 2013) de certos modos de exercício da docência. Considerando-se essas colocações, justifica-se a importância de empreender uma analítica das práticas de governamento (DEAN, 1999), demonstrando os modos como as obras, enquanto vetores de uma pedagogia histórico-crítica, regulam as condutas docentes, incitando a construção de sentidos interessados e naturalizados sobre como deverá atuar o professor delineado nas publicações.

Tendo apresentado a produtividade dos conceitos de discurso (FOUCAULT, 2005, 2007) e governamento (DEAN, 1999; FOUCAULT, 2008), na próxima seção, será discutida a arquitetura formativa dos livros que constituíram o material de análise, ou seja, as regularidades presentes no modo como são organizadas as obras.

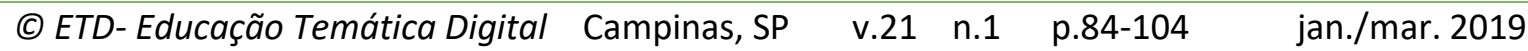




\section{A ARQUITETURA FORMATIVA DOS LIVROS QUE CONSTITUÍRAM A MATERIALIDADE INVESTIGATIVA}

Queremos possibilitar a nossas crianças o desenvolvimento integral desde bebês e, para isso, pensamos esse livro como uma ferramenta teórica, didática e metodológica, a instigar e a inspirar o trabalho de futuros e atuais professores. (ARCE, 2014, p. 10)

O objetivo da seção é evidenciar, por meio da apresentação da arquitetura formativa (BOCCHETTI; BUENO, 2012) das obras integrantes da materialidade investigativa da pesquisa, que a preocupação central das organizadoras/autoras dos livros não se restringe ao conteúdo dos textos abordados nos capítulos, mas também envolve o uso de táticas discursivas (SOBRAL, 2013) de vinculação dos leitores aos argumentos defendidos. Em outras palavras, a arquitetura dos livros aciona o funcionamento de práticas dirigidas ao governamento docente. Isso equivale a afirmar que os livros procuram conferir visibilidade às verdades pedagógicas que veiculam, assim como promovem a operacionalização de táticas discursivas de persuasão que garantam que tais verdades sejam apresentadas e continuamente reiteradas junto ao leitor (PEREIRA; RATTO, 2008).

A partir do exposto, convém apresentar os títulos elucidativos dos livros, já que, em resumo, podem ser considerados uma prévia dos assuntos por eles abordados: 1) 'Ensinando aos pequenos de zero a três anos' (ARCE; MARTINS, 2009); 2) 'Quem tem medo de ensinar na Educação Infantil?: em defesa do ato de ensinar' (ARCE; MARTINS, 2010); 3) 'Ensinando ciências na Educação Infantil' (ARCE; SILVA; VAROTTO, 2011); 4) 'Educação Infantil versus Educação Escolar?: entre a (des)escolarização e a precarização do trabalho pedagógico nas salas de aula' (ARCE; JACOMELLI, 2012); 5) 'Interações e brincadeiras na Educação Infantil' (ARCE; 2013); 6) 'Trabalho pedagógico com crianças de até três anos' (ARCE, 2014).

Particularmente, em relação aos títulos, é evidente a repetição da defesa do ato de ensinar (ARCE; MARTINS, 2009; ARCE; MARTINS, 2010; ARCE; SILVA; VAROTTO, 2011) na Educação Infantil. Com efeito, com base em Popkewitz (2001, p. 33), essa defesa do ensino pode ser entendida como uma espécie de "discurso de salvação" que significa os bebês e as crianças pequenas "como indivíduos que não são justos, capazes e competentes, mas que com atenção, cuidado" e ensino adequados podem ser salvos. Além disso, pode-se perceber, em um dos títulos, a oposição (embora apresentada por meio de uma questão) entre Educação Infantil e Educação Escolar (ARCE; SILVA; VAROTTO, 2011), cujo efeito, de acordo com as autoras, é a (des)escolarização e a precarização do trabalho docente exercido nas salas de aula. Dessa forma, as obras, desde os títulos, indicam tendências, repetem argumentos e enfatizam um determinado modo de entender a docência com as crianças pequenas. Por se pautarem na máxima de que a Educação Infantil deve desenvolver um trabalho pedagógico docente "sistematicamente ancorado nos domínios da ciência" (ARCE,

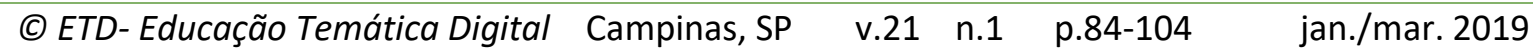


2009 , p. 16), as obras analisadas reiteram que os professores da primeira etapa da Educação Básica devem ser responsáveis "pela transmissão planejada de conhecimentos historicamente sistematizados" (MARTINS; ARCE, 2010, p. 3).

Prosseguindo a discussão, outros aspectos relevantes de serem referidos em relação à arquitetura formativa (BOCCHETTI; BUENO, 2012) das obras é o fato de elas: a) pautaremse nas contribuições da pedagogia histórico-crítica, enquanto espécie de expertise, para apresentar e justificar uma didática do trabalho docente com bebês e crianças pequenas guiada pelo ensino de conteúdos; b) sempre iniciarem com a apresentação de um especialista em educação, o qual sumariza os aspectos das obras precedentes e ratifica a importância dos textos que estão sendo veiculados; c) possuírem um forte acento didáticometodológico;

d) serem organizadas pelas mesmas autoras em quase todas as edições, configurando, desse modo, uma coleção; e) serem coletâneas constituídas por textos produzidos por pedagogos e especialistas em áreas específicas do conhecimento língua portuguesa, ciências, matemática, etc. -, os quais descrevem detalhadamente como devem ser ensinados os conteúdos para as crianças; f) apresentarem argumentos elaborados a partir de críticas à pedagogia da infância, cujos pressupostos remontam à filosofia da consciência.

Adentrando o conteúdo das obras, há ainda que se destacar as práticas de governamento ético presentes na arquitetura formativa (BOCCHETTI; BUENO, 2012) dos livros, cujo intuito é operar na regulação moral do professor com base na aproximação e no estabelecimento de vínculo com ele. Em geral, por meio dessas práticas, o professor é convocado a identificar-se com um modo específico de exercício da docência, além de ser incitado a refletir sobre suas necessidades profissionais. A seguir, serão apresentadas algumas estratégias de aproximação entre as autoras e os leitores do texto, empregadas de forma recorrente nas obras analisadas.

O educador deve agir com o bebê de modo a estimulá-lo, assim, este irá se desenvolver de modo integral. Nesse ponto, o professor pode estar se perguntando: mas como fazer isso? $O$ que propor no trabalho pedagógico com bebês? (SILVA, 2013, p. 63)

É possível que a média dos leitores estranhe a proposta dos autores de centrar a educação de crianças na faixa etária de 0 a 3 anos no ensino. Provavelmente indagarão exclamando: mas como! Ensinar crianças na creche? (SAVIANI, 2009, p. 9)

Encerramos esta primeira parte do texto afirmando que a criança não cria cultura, mas se apropria da cultura existente reproduzindo-a e modificando-a, o leitor poderia perguntar-se: a criança pequena não cria? Mas como a criança menor de 3 anos é capaz de dar resposta às questões do cotidiano de forma tão criativa? Não é a criatividade uma marca desta criança e que nós adultos perdemos no decorrer de nossas vidas? Ou melhor, não foi o fato de recebermos uma educação repetitiva e baseada na reprodução que nos fez perder essa criatividade natural infantil? (ARCE; BALDAN, 2009, p. 197-198)

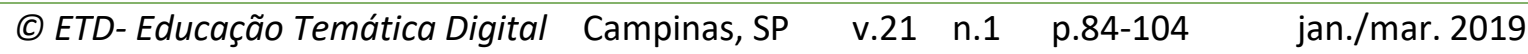


Com base na leitura dos excertos, percebe-se uma comunicação direta com o leitor, cujo intuito é colocá-lo em uma condição reflexiva (BOCCHETTI; BUENO, 2012), acompanhada da definição de aspectos que devem pautar seus questionamentos. Em tal perspectiva, é evidente o constante processo de convocação do leitor para o texto, no intuito de que seja estabelecida uma relação de cumplicidade com os argumentos apresentados pelas autoras e uma filiação ao "conhecimento especializado" (GARCIA, 2002; BOCCHETTI; BUENO, 2012) sobre a educação de bebês e crianças pequenas enunciado nas obras. Ratificando a exposição realizada, é importante destacar que o poder do conhecimento especializado difundido nos livros "está no fato do mesmo não ser apenas conhecimento, mas também uma forma de modelar a maneira como os professores participam como sujeitos ativos e responsáveis" (POPKEWITZ, 2001, p. 13) das decisões a respeito de seus modos de exercício profissional.

Do ponto de vista analítico, o governamento se encontra diretamente relacionado ao modo como os professores, enquanto indivíduos livres e responsáveis, são incitados a governar a si mesmos (GORDON, 1991; DEAN, 1999; FOUCAULT, 2008). Trata-se de uma liberdade regulada, que não opera por meio da subordinação do leitor (MARÍN-DIÁZ, 2012), mas através de um conjunto de sofisticadas estratégias promotoras de desejos, reflexões, escolhas e decisões. Isso significa que se governa à distância, fazendo com que o leitor acredite ser governante de si mesmo (BUJES, 2009).

Prosseguindo a discussão, na próxima seção, serão apresentadas as táticas discursivas (SOBRAL, 2013) presentes nas obras analisadas, evidenciando os modos como operam no governamento (DEAN, 1999; FOUCAULT, 2008; DARDOT; LAVAL, 2016) docente, através da difusão de "sensibilidades, disposições e conscientizações" (POPKEWITZ, 2001) que ratificam a defesa do ato de ensinar bebês e crianças pequenas com base em uma pedagogia histórico-crítica.

\section{A DEFESA DO ATO DE ENSINAR NA CRECHE: PRÁTICAS DE GOVERNAMENTO EM OPERAÇÃO}

Repetições, contrastes e exemplos (SOBRAL, 2013) - eis as três táticas discursivas recorrentes em todas as obras analisadas. É a partir dessas táticas constituidoras de uma determinada ordem pedagógica que o leitor "aprende a ver-se, a dizer-se e a julgar-se" (LARROSA, 1994) enquanto professor de crianças. Ou seja, o leitor aprende "a produzir o seu duplo e a sujeitar-se a ele" (LARROSA, 1994, p. 80). Cabe esclarecer que esse duplo é composto pelo eu que o indivíduo observa quando se vê, "do eu que expressa quando se diz a si mesmo, do eu que narra quando constrói sua identidade, do eu que julga quando aplica um critério e do eu que domina quando se governa" (LARROSA, 1994, p. 80). Por conseguinte, pode-se dizer que é através dessa "produção do duplo" (LARROSA, 1994) que determinadas racionalidades éticas (MARÍN-DÍAZ, 2012) são inscritas nas "sensibilidades,

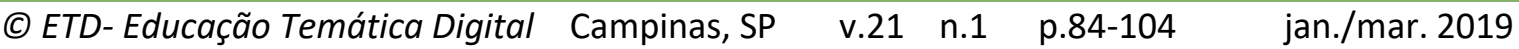


disposições e na consciência" (POPKEWITZ, 2001) dos leitores, habilitando-os para o exercício de uma docência pautada na pedagogia histórico-crítica.

Para melhor compreender essa investida, em primeiro lugar, convém apresentar a repetição (SOBRAL, 2013), já que esta se configurou como uma potente tática educativa utilizada pelas autoras para destacar a importância do ato de ensinar conteúdos escolares para as crianças na Educação Infantil. Isso porque se produz, "pela repetição e pela alienação teórica, um certo traçado na língua" (PEREIRA; RATTO, 2008, p. 8) que opera no condicionamento da compreensão do leitor. Nessa direção, torna-se importante observar os excertos das obras apresentados a seguir:

A partir da defesa do ato de ensinar realizado neste livro ficará claro que o trabalho na educação infantil não pode prescindir de ser organizado por áreas de conhecimento. (ARCE, 2010, p. 35)

[...] é possível e necessário ensinar aos bebês. O professor deve ver-se como o profissional que possui o conhecimento teórico e prática para realizar uma revolução na vida do bebê ao apresentá-lo ao mundo natural humanizado. (ARCE; SILVA, 2009, p. 183)

O professor retoma seu status daquele que ensina, que provoca o desenvolvimento através da transmissão de conhecimentos. (ARCE, 2010, p. 32)

Defender o ensino de ciências para a educação infantil é algo encampado por vários autores nacionais e internacionais. (ARCE; SILVA; VAROTTO, 2011, p. 61)

Procuramos mostrar que o ensino permeia todo o processo educativo na educação infantil. (ARCE, 2013, p. 37)

[...] procuramos trabalhar com a desconstrução da ideia de que ensinar é algo maléfico. (ARCE, 2014, p. 10)

Como indica o título do livro, o tema central gira em torno da importância do ensino na educação de crianças pequenas. (SAVIANI, 2009, p. 7)

Assim, nosso objetivo, neste capítulo, é mostrar que o trabalho com bebês vai além do simples cuidado, tendo como eixo o ensino. (SILVA, 2013, p. 42)

Como é possível observar com a leitura, a abundância da repetição da defesa do ato de ensinar expressa o quanto esse enunciado é tomado de modo naturalizado como princípio fundador de uma pedagogia histórico-crítica que torna a docência passível de intervenção e regulação. Isso significa que, nesse contexto, a repetição é fundamental para que o discurso da escolarização das crianças pequenas produza os efeitos esperados. Nesse sentido, as autoras das obras analisadas, com o uso dessa tática discursiva reiterativa, indicam uma didática difusora da pedagogia defendida, apresentando detalhadamente aos leitores vocabulários compartilhados e orientações sobre o que e como devem ser ensinados os bebês e as crianças pequenas. Dentro dessa lógica, são prescritos princípios pedagógicos que operam o governamento docente (FOUCAULT, 2008) por meio da repetição e ratificação das verdades produzidas.

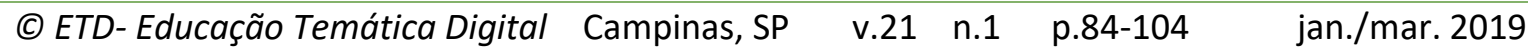


Prosseguindo com o propósito de que os leitores alcancem o entendimento das informações veiculadas nos livros, também é utilizada, de modo recorrente, a tática discursiva do contraste (SOBRAL, 2013). Particularmente, em relação a essa tática, pode-se afirmar que opera através de comparações entre a pedagogia da infância e a pedagogia histórico-crítica, com o propósito de incitar o leitor a tornar-se aliado das autoras dos livros, no árduo desafio de alcançar as metas educacionais declaradas. Para tanto, com o uso do poder reiterativo dos contrastes entre as referidas pedagogias, "fabricam-se corredores isotópicos" (PEREIRA; RATO, 2008, p. 7), objetivando que o leitor acredite que é livre para realizar suas escolhas e que, caso trabalhe conforme as orientações descritas nas obras, estará contribuindo para a renovação da prática pedagógica na Educação Infantil. Acerca dos contrastes, será possível verificar a presença de tal tática nos excertos apresentados na sequência:

As análises empreendidas nesta obra não compartilham com ideários que fetichizam a existência das crianças pequenas [...]. (ARCE; MARTINS, 2009, p. 16)

[...] trabalharemos e discutiremos neste texto o que consideramos no trabalho com os bebês como a 'estimulação necessária', em oposição ao conceito de 'estimulação precoce' dos bebês. (ARCE; SILVA, 2009, p. 164)

[...] a educação infantil apresenta desde a sua origem uma tendência ao esvaziamento do ensino. (STEMMER, 2012, p. 27)

Podemos perceber os rumos que a educação infantil e a formação de seus professores estão tomando. Na busca das especificidades da infância e oposição ao pensamento moderno, acabam por se adaptarem ao que tem sido chamado de 'agenda pós-moderna'. (PRADO; AZEVEDO, 2012, p. 46)

Assim, a instituição de educação infantil passa a ser um 'paraíso' para que as crianças possam exercitar sua curiosidade, possam brincar e se refugiar da realidade social que corrompeu sua natureza. (PRADO; AZEVEDO, 2012, p. 47)

Como se pode observar, "o governamento da subjetividade docente utiliza-se de táticas para agir sobre as escolhas, os desejos e a conduta dos leitores, ainda que de forma indireta" (BUJES, 2009, p. 282). A partir da apresentação recorrente de contrastes nos textos, as autoras dos livros defendem a imprescindibilidade de que o desenvolvimento infantil seja provocado através da transmissão de conhecimentos (ARCE, 2010) às crianças.

Para atender a tática do contraste, as autoras apresentam sempre em seus textos uma "narrativa de crise pautada em um tom apocalíptico" (LARROSA, 2004, p. 210), o qual, por meio de reiteradas críticas, vincula a pedagogia da infância a um ideário pós-moderno (STEMMER, 2012), cujo efeito previsto é a precarização do trabalho docente e a (des)escolarização das crianças na Educação Infantil (ARCE; MARTINS, 2009, 2010; ARCE; JACOMELLI, 2012). Nesse sentido, é possível afirmar que a pedagogia da infância é nomeada, nas obras analisadas, como sendo antiescolar (ARCE; JACOMELLI, 2012), pelo fato

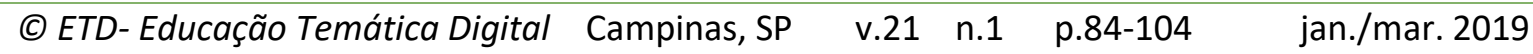


de, dentre outros aspectos: 1) focalizar o trabalho educativo em aprendizagens individuais (PINA, 2014); 2) não admitir a ideia de que é o adulto que humaniza a criança (PINA, 2014); 3) defender o princípio lúdico como fundamento da prática educativa (ARCE, 2013); 4) negar 0 ato de ensinar ao centrar-se no binômio cuidar-educar (ARCE; MARTINS, 2010; ARCE, 2014); 5) focalizar as chamadas relações educativo-pedagógicas, e não o processo de ensino-aprendizagem (PASQUALINI, 2010). É sobretudo com a crítica à pedagogia da infância que as autoras das obras constroem e defendem a operacionalização de uma pedagogia histórico-crítica desde a creche.

Tendo situado, em termos gerais, as táticas de repetição e contraste encontradas nas obras que constituíram a materialidade investigativa da pesquisa, torna-se imprescindível apresentar a tática discursiva do exemplo (SOBRAL, 2013). Partindo do pressuposto de que "a pedagogia se sustenta sobre uma fiç̧ão vertical" (LARROSA, 2004, p. 278), na qual existe a necessidade de "adquirir certa legitimidade para olhar os outros de cima, para falar deles, para lançar sobre eles certos projetos de reforma ou de melhoramento" (LARROSA, 2004, p. 278), os exemplos de práticas pedagógicas compartilhadas nos livros podem ser vistos como "modos de exercitação destinados à modificação dos sujeitos" (MARÍN-DÍAZ, 2012, p. 37) docentes. Na direção do que foi exposto, serão apresentados a seguir alguns excertos referentes à tática discursiva do exemplo:

As atividades que passaremos a descrever e analisar são elucidativas deste e de outros fundamentos discutidos ao longo deste capítulo e que serão, de certo modo, retomados adiante. (BARBOSA, 2013, p. 124)

O que vemos nessa cena? Uma professora que garante em sua rotina a leitura de livros de literatura e que planeja uma roda sensível às peculiaridades de uma turma de berçário. (BRANDÃO; ROSA, 2014, p. 56)

[...] apresentaremos alguns exemplos de planos de ensino, de forma sintética, a título de ilustração, pautado na interação do educador com os bebês, uma vez que a comunicação emocional direta é a atividade principal desta faixa etária. (SILVA, 2013, p. 65)

Qual seria o caminho para uma aula de ciências a partir do que expomos? [...] o professor deve sempre levar a criança ao questionamento e a partir deste iniciar o processo investigativo. Mas como faço para levar as crianças a questionar? Podese por exemplo partir de um livro de literatura infantil, ou levar as crianças a observar algo fomentando o questionar delas. (ARCE; SILVA; VAROTTO, 2011, p. 83)

Caberá a ele (adulto), por meio da comunicação verbal com a criança, dar a conhecer os objetos que a rodeiam, denominando-os, considerando seus significados e usos sociais, suas propriedades físicas mais evidentes (tamanho, cor, textura, forma etc). Este é o início do caminho pelo qual a criança aprenderá a discriminar, analisar e diferenciar os objetos e fenômenos em suas propriedades mais importantes. (MARTINS, 2009, p. 105)

Os excertos destacados permitem inferir que os exemplos descritos nas obras não constituem apenas uma didática para o trabalho pedagógico, como também uma sofisticada (C) ETD-Educação Temática Digital Campinas, SP $\quad$ v.21 n.1 $\quad$ p.84-104 jan./mar. 2019 
estratégia através da qual a subjetividade docente é demandada, fabricada e difundida por meio de enunciados que constituem o discurso da pedagogia escolar na Educação Infantil. Isso significa que os exemplos de como deve ser a atuação docente, além de promoverem a regulação social, produzem estilos privilegiados de raciocínio (POPKEWITZ, 2002) que operam diretamente no governamento (DEAN, 1999; FOUCAULT, 2008; DARDOT; LAVAL, 2016) docente. Além disso, pode-se afirmar que os exemplos compartilhados nas obras constituem uma determinada ordem pedagógica que "não para de cultivar o dispositivo da explicação, de estilizá-lo, de aperfeiçoá-lo, de embelezá-lo e redefini-lo" (LARROSA, 2004, p. 279), com o intuito de que o leitor produza o seu duplo (LARROSA, 1994) e transforme a si mesmo no professor descrito nas publicações.

Enfim, tendo em vista a conclusão desta seção, cabe afirmar que as táticas de repetição, contraste e exemplos (SOBRAL, 2013), presentes em todas as obras analisadas, incidem indefectivelmente na promoção da mediação pedagógica (LARROSA, 1994) do leitor consigo mesmo. Isso indica que tal mediação objetiva a produção do leitor enquanto um determinado tipo de professor de Educação Infantil que aprende a "ver-se, a dizer-se e a julgar-se" (LARROSA, 1994), a partir dos preceitos enunciados pela pedagogia históricocrítica. Prosseguindo a discussão, na próxima seção serão apresentadas as considerações finais.

\section{CONSIDERAÇÕES FINAIS}

Toda e qualquer pedagogia constitui "sistemas de conhecimento" (POPKEWITZ, 1998) produtores de modos de atuação e de indicadores de avaliação, através dos quais os professores avaliam a si próprios em busca da qualificação de suas práticas. Em outras palavras, a pedagogia trata "de definir, formar e transformar um professor, capaz de examinar e reexaminar, regular e modificar, tanto sua própria atividade prática quanto a si mesmo" (LARROSA, 1994, p. 49). Isso porque "o conhecimento da pedagogia é um elemento constitutivo e material do mundo contemporâneo" (POPKEWITZ, 2001, p. 26). Com base nos referidos pressupostos, é importante reiterar que o objetivo das discussões apresentadas no decorrer do artigo foi problematizar as práticas de governamento (FOUCAULT, 2008) docente que operam por meio do discurso da pedagogia histórico-crítica presente nas obras analisadas. Ou seja, são práticas de governamento que, com táticas discursivas (SOBRAL, 2013), promovem a formação de um professor que defende a transmissão de conhecimentos (PASQUALINI, 2010) como base fundamental do trabalho pedagógico em sala de aula com as crianças na Educação Infantil.

Nessa perspectiva, cabe esclarecer que não houve interesse em estabelecer um juízo de valores a respeito da pedagogia histórico-crítica veiculada nos livros, mas evidenciar a

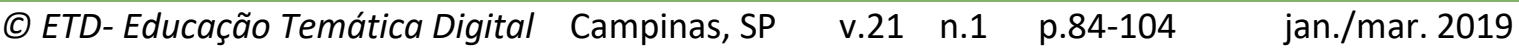


centralidade desse discurso na difusão e manutenção de uma determinada ordem pedagógica (LARROSA, 2004) que toma a defesa do ensino de conteúdos por áreas de conhecimento para bebês e crianças pequenas como premissa básica do trabalho docente. E é justamente por isso que convém afirmar que o discurso de tal pedagogia se constitui em apenas uma das formas de entender a docência na Educação Infantil. Nesse sentido, é imprescindível destacar a contingência dos discursos pedagógicos, ou seja, o fato de que, embora os indivíduos sejam "menos livres do que pensam quando falam, julgam ou fazem coisas" (LARROSA, 1994, p. 84), sempre existirá a possibilidade de "falar de outros modos, de julgar de outros modos, de conduzir-se de outras maneiras" (LARROSA, 1994, p. 84), para além dos regimes de verdade (FOUCAULT, 2007) que insistem em definir um modelo exclusivo de atuação docente.

Tendo em vista as considerações expostas, durante o decorrer do artigo, foi descrita a "arquitetura formativa dos livros" (BOCCHETTI; BUENO, 2012), destacando que "as linhas de raciocínio apresentadas nos textos se inscrevem segundo um regime de verdade" (PEREIRA; RATTO, 2008, p. 7) cujo "conteúdo obedece a um conjunto de regras, dadas historicamente" (PEREIRA; RATTO, 2008, p. 7). Do mesmo modo, foram discutidas as "táticas discursivas - de repetição, contraste e exemplos" (SOBRAL, 2013) - presentes no material analisado. Nesse sentido, por meio das análises apresentadas, foram evidenciadas as práticas de governamento (FOUCAULT, 2008; DARDOT; LAVAL, 2016) que investem para que os professores se reconheçam como ideal e potencialmente certo tipo de profissional.

Por fim, com base em todos os aspectos discutidos, destaca-se que o exercício de análise das práticas de governamento presentes nos livros de formação docente possibilitou problematizar a naturalização dos enunciados constituintes do discurso da pedagogia histórico-crítica. Isso porque, como lembra Popkewitz (2001, p. 141), “o papel de um pesquisador não é o de dizer aos outros o que tem de fazer, não é moldar a vontade política dos outros, mas ao invés disso, é o de questionar incessantemente o que é postulado como auto-evidente". Afinal, assumir a dimensão constitutiva da linguagem e enfrentar o desafio de questionar os efeitos de verdade dos discursos que operam no governamento da formação docente se configura uma importante atitude ética na atualidade.

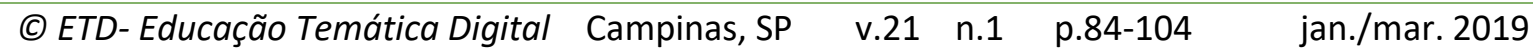




\section{REFERÊNCIAS}

ARCE, Alessandra. Como pensar e organizar o trabalho pedagógico na Educação Infantil? contribuições da teoria histórico-cultural. In: PAGNONCELLI, Cláudia; MALANCHEN, Julia; MATOS, Neide da Silveira Duarte. 0 trabalho pedagógico nas disciplinas escolares: contribuições a partir dos fundamentos da pedagogia histórico-crítica. Campinas, SP: Armazém do Ipê, 2016. p. 95-110.

ARCE, Alessandra. É possível falar em Pedagogia Histórico-Crítica para pensarmos a Educação Infantil? Germinal: marxismo e educação em debate, Salvador, v. 5, n. 2, p. 5-12, dez. 2013.

ARCE, Alessandra (Org.). Interações e brincadeiras na educação infantil. Campinas, SP: Alínea, 2013.

ARCE, Alessandra. O Referencial Curricular Nacional para a Educação Infantil e o espontaneísmo: (re)colocando o ensino como eixo norteador do trabalho pedagógico com crianças de 4 a 6 anos. In: ARCE, Alessandra; MARTINS, Ligia M. (Org.). Quem tem medo de ensinar na Educação Infantil? em defesa do ato de ensinar. Campinas, SP: Alínea, 2010. p. 13-36.

ARCE, Alessandra (Org.). Trabalho pedagógico com crianças de até três anos. Campinas, SP: Alínea, 2014.

ARCE, Alessandra; BALDAN, Merilin. A criança menor de três anos produz cultura? criação e reprodução em debate na apropriação da cultura por crianças pequenas. In: ARCE, Alessandra; MARTINS, Ligia M. (Org.). Ensinando aos pequenos de zero a três anos. Campinas, SP: Alínea, 2009. p. 187-204.

ARCE, Alessandra; JACOMELLI, Mara Regina Martins (Org.). Educação infantil versus educação escolar? entre a (des)escolarização e a precarização do trabalho pedagógico nas salas de aula. Campinas, SP: Autores Associados, 2012.

ARCE, Alessandra; MARTINS, Ligia M. (Org.). Ensinando aos pequenos de zero a três anos. Campinas, SP: Alínea, 2009.

ARCE, Alessandra; MARTINS, Ligia M. (Org.). Quem tem medo de ensinar na educação infantil? em defesa do ato de ensinar. Campinas, SP: Alínea, 2010.

ARCE, Alessandra; SILVA, Débora A. S.; VAROTTO, Michele. Ensinando ciências na educação infantil. Campinas, SP: Alínea, 2011.

ARCE, Alessandra; SILVA, Janaína Cassiano. É possível ensinar no berçário? o ensino como eixo articulador do trabalho com bebês (6 meses a 1 ano de idade). In: ARCE, Alessandra; MARTINS, Ligia M. (Org.). Ensinando aos pequenos de zero a três anos. Campinas, SP: Alínea, 2009. p. 163-186.

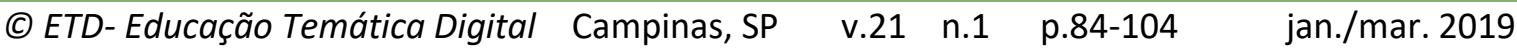


BARBOSA, Eliza Maria. Interações, aprendizagens e desenvolvimento humano em contextos escolares para a infância. In: ARCE, Alessandra (Org.). Interações e brincadeiras na educação infantil. Campinas, SP: Alínea, 2013. p. 113-140.

BARBOSA, Maria Carmem Silveira. Pedagogia da infância. In: OLIVEIRA, Dalila Andrade; DUARTE, Adriana Cancella; VIEIRA, Lívia Fraga. Dicionário: trabalho, profissão e condição docente. Belo Horizonte: UFMG/Faculdade de Educação, 2010. p. 10-12.

BOCCHETTI, André; BUENO, Belmira Oliveira. Um professor (sempre) a formar: o governo das subjetividades docentes em programas especiais de formação. Currículo sem Fronteiras, v. 12, n. 2, p. 376-392, maio/ago. 2012.

BRANDÃO, Ana Carolina Perrusi; ROSA, Ester Calland de Sousa. In: ARCE, Alessandra (Org.). Trabalho pedagógico com crianças de até três anos. Campinas, SP: Editora Alínea, 2014. p. 37-58.

BUJES, Maria Isabel Edelweiss. Manuais pedagógicos e formação docente: elos de poder/saber. Currículo sem Fronteiras, v. 9, n. 1, p. 267-288, jan./jun. 2009.

DARDOT, Pierre; LAVAL, Christian. A nova razão do mundo: ensaio sobre a sociedade neoliberal. São Paulo: Bointempo, 2016.

DEAN, Mitchell. Governamentality, power and rule in modern society. London: Thousand Oaks; New Delhi: Sage Publications, 1999.

FOUCAULT, Michel. A arqueologia do saber. Rio de Janeiro: Forense Universitária, 2007.

FOUCAULT, Michel. A ordem do discurso. São Paulo: Loyola, 2005.

FOUCAULT, Michel. Microfísica do poder. Rio de Janeiro: Graal, 1995.

FOUCAULT, Michel. Segurança, território e população. São Paulo: Martins Fontes, 2008.

GARCIA, Maria Manuela Alves. Pedagogias críticas e subjetivação: uma perspectiva foucaultiana. Rio de Janeiro: Vozes, 2002.

LARROSA, Jorge. Linguagem e educação depois de Babel. Belo Horizonte: Autêntica, 2004.

LARROSA, Jorge. Tecnologias do eu e educação. In: SILVA, Tomaz Tadeu (Org.). Sujeito da educação: estudos foucaultianos. Petrópolis: Vozes, 1994. p. 35-86.

LAZARETTI, Lucinéia Maria; MELLO, Maria Aparecida. Como ensinar na Educação Infantil? reflexões sobre a didática e o desenvolvimento da criança. In: PASQUALINI, Juliana Campregher; TEIXEIRA, Lucas André; AGUDO, Marcela de Moraes. Pedagogia históricocrítica: legado e perspectivas. Uberlândia: Navegando Publicações, 2018. p. 117-134.

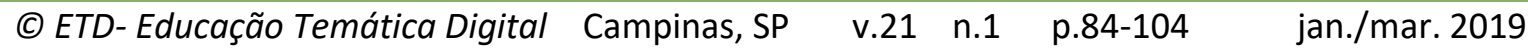


MARÍN-DÍAZ, Dora Lilia. Autoajuda e educação: uma genealogia das antropotécnicas contemporâneas. 2012. 491 f. Tese (Doutorado em Educação) - Programa de PósGraduação em Educação, Faculdade de Educação, Universidade Federal do Rio Grande do Sul, Porto Alegre, 2012.

MARÍN-DÍAZ, Dora Lilia; NOGUERA-RAMIREZ, Carlos. Educar es gobernar. In: SALCEDO, Ruth Amanda Cortés; MARÍN-DÍAZ, Dora Lilia. Gobernamentalidad y educación: discusiones contemporáneas. Bogotá: Instituto para Investigación Educativa y el Desarrollo Pedagógico (IDEP), 2011. p. 127-151.

MARTINS, Ligia M. O ensino e o desenvolvimento da criança de zero a três anos. In: ARCE, Alessandra; MARTINS, Ligia M. (Org.). Ensinando aos pequenos de zero a três anos. Campinas, SP: Alínea, 2009. p. 93-122.

MINISTÉRIO DA EDUCAÇÃO. Base Nacional Comum Curricular. Brasília: MEC, 2017.

MINISTÉRIO DA EDUCAÇÃO. Conselho Nacional de Educação. Câmara de Educação Básica. Resolução n.ㅇ 5, de 17 de dezembro de 2009. Fixa as Diretrizes Curriculares Nacionais para a Educação Infantil. Diário Oficial da União, Brasília, DF, 18 dez. 2009, Seção 1, p. 18.

PALAMIDESSI, Mariano Ismael. La producción del "maestro constructivista" en el discurso curricular. Educação e Realidade, Porto Alegre, v. 1, n. 2, p. 191-213, jul./dez. 1996.

PASQUALINI, Juliana Campregher. Construção e implementação de uma proposta pedagógica para a Educação Infantil: reflexões e indicativos para a ação concreta. In: PASQUALINI, Juliana Campregher; TEIXEIRA, Lucas André; AGUDO, Marcela de Moraes. Pedagogia histórico-crítica: legado e perspectivas. Uberlândia: Navegando Publicações, 2018. p. 191-212.

PASQUALINI, Juliana Campregher. O papel do professor e do ensino na Educação Infantil: a perspectiva de Vigotski, Leontiev e Elkonin. In: MARTINS, Lígia Márcia; DUARTE, Newton (Org.). Formação de professores: limites contemporâneos e alternativas necessárias. São Paulo: Editora UNESP, Cultura Acadêmica, 2010. p. 161-199.

PEREIRA, Marcos Villela; RATTO, Cléber Gibbom. Rastros del fundamentalismo pedagógico en la formación de profesores. Archivos de Ciencias de la Educación, Argentina, v. 2, n. 2, p. 121-135, nov. 2008.

PINA, Leonardo Docena. A prática pedagógica histórico-crítica e o ensino de Educação Física na Educação Infantil. Revista Histedbr On-line, Campinas, n. 59, p. 129-150, out. 2014.

POPKEWITZ, Thomas. História do currículo, regulação social e poder. In: SILVA, Tomaz Tadeu da (Org.). O sujeito da educação: estudos foucaultianos. Petrópolis, RJ: Vozes, 2001. p. 173210.

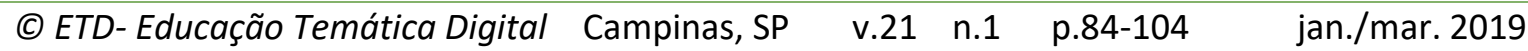


POPKEWITZ, Thomas. Lutando em defesa da alma: a política do ensino e a construção do professor. Porto Alegre: Artes Médicas, 1998.

PRADO, Alessandra Elizabeth Ferreira Gonçalves; AZEVEDO, Heloísa Helena Oliveira. Currículo para a educação infantil: argumentos acadêmicos e propostas de "educação" para crianças de 0 a 5 anos. In: ARCE, Alessandra; JACOMELLI, Mara Regina Martins (Org.). Educação infantil versus educação escolar? entre a (des)escolarização e a precarização do trabalho pedagógico nas salas de aula. Campinas, SP: Autores Associados, 2012. p. 33-52.

ROCHA, Eloisa Acires Candal. A pedagogia e a educação infantil. Revista Brasileira de Educação, n. 16, p. 27-34, jan./abr. 2001.

SAVIANI, Dermeval. Pedagogia histórico-crítica: primeiras aproximações. Campinas, SP: Autores Associados, 2000.

SAVIANI, Dermeval. Prefácio. In: ARCE, Alessandra; MARTINS, Ligia M. (Org.). Ensinando aos pequenos de zero a três anos. Campinas, SP: Alínea, 2009. p. 7-14.

SILVA, Janaína. É hora de trocar a fralda! contribuições da teoria histórico-cultural para o trabalho com bebês na educação infantil. In: ARCE, Alessandra (Org.). Interações e brincadeiras na educação infantil. Campinas, SP: Alínea, 2013. p. 41-72.

SOBRAL, Antônio Luís Tubino. Sintaxes pedagógicas no fotojornalismo da Veja sobre o agronegócio. 2013. 93 f. Dissertação (Mestrado em Educação) - Programa de PósGraduação em Educação, Faculdade de Educação, Universidade Luterana do Brasil, Canoas, 2013.

STEMMER, Márcia Regina Goulart. Educação Infantil: gênese e perspectivas. In: ARCE, Alessandra; JACOMELLI, Mara Regina Martins (Org.). Educação infantil versus educação escolar? entre a (des)escolarização e a precarização do trabalho pedagógico nas salas de aula. Campinas, SP: Autores Associados, 2012. p. 5-32.

VEIGA-NETO, Alfredo. A ordem das disciplinas. 1996. 230 f. Tese (Doutorado em Educação) - Programa de Pós-Graduação em Educação, Faculdade de Educação, Universidade Federal do Rio Grande do Sul, Porto Alegre, 1996.

VEIGA-NETO, Alfredo. Coisas de governo. In: RAGO, Margareth; ORLANDI, Luz Lacerda; VEIGA-NETO, Alfredo (Org.). Imagens de Foucault e Deleuze: ressonâncias nietzschianas. Rio de Janeiro: DP\&A, 2002. p. 9-12.

Revisão gramatical do texto sob responsabilidade de:

Isabela Beraldi Esperandio.

E-mail: isabela_esperandioyahoo.com.br

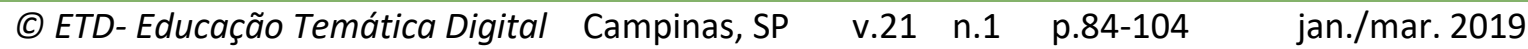

